livraisons

d'Histoire

de l'Architecture

\section{Livraisons de l'histoire de l'architecture}

41 | 2021

L'architecte en son agence

\title{
Vers une politique organique des « Beaux-arts»: Louis Hautecœur et la leçon de Paul Léon
}

Towards organic politics of "Fine Arts": LouisHautecour and the lesson of Paul Léon

Auf dem Weg zu einer "organischen" Politik der Beaux-Arts: Louis Hautecœur und die Lehre Paul Léons

\section{Antonio Brucculeri}

\section{OpenEdition}

\section{Journals}

Édition électronique

URL : https://journals.openedition.org//ha/2935

DOI : $10.4000 /$ /ha.2935

ISSN : 1960-5994

\section{Éditeur}

Association Livraisons d'histoire de l'architecture - LHA

Référence électronique

Antonio Brucculeri, «Vers une politique organique des «Beaux-arts » : Louis Hautecœur et la leçon de Paul Léon », Livraisons de l'histoire de l'architecture [En ligne], 41 | 2021, mis en ligne le 15 juin 2021, consulté le 19 juin 2021. URL : http://journals.openedition.org//ha/2935 ; DOI : https://doi.org/ 10.4000/lha. 2935

Ce document a été généré automatiquement le 19 juin 2021.

Tous droits réservés à l'Association LHA 


\title{
Vers une politique organique des « Beaux-arts » : Louis Hautecœur et la leçon de Paul Léon
}

\author{
Towards organic politics of "Fine Arts": LouisHautecour and the lesson of Paul \\ Léon \\ Auf dem Weg zu einer "organischen" Politik der Beaux-Arts: Louis Hautecœur \\ und die Lehre Paul Léons
}

Antonio Brucculeri

1 Les relations entre Louis Hautecœur (1884-1973) et Paul Léon (1874-1962) s'inscrivent dans la longue durée, et sont attestées jusqu'aux dernières années de leur existence. La correspondance privée de Hautecœur montre l'existence d'un lien solide ${ }^{1}$, confirmé en 1954 par Léon qui affichait publiquement «la fidèle amitié qui depuis de longues années a rapproché nos deux vies $»^{2}$. Quelques années plus tard, en 1962, c'est Hautecœur qui rédigea la notice nécrologique de Léon, à la demande du fils de ce dernier, dans les Annales des anciens élèves de l'École normale supérieure ${ }^{3}$, l'établissement dont ils avaient partagé l'expérience de la formation, bien qu'à une génération d'écart, attirés l'un par la géographie, l'autre par l'histoire4. Hautecœur y exprimait sa dette envers le haut fonctionnaire dont il avait été "un collaborateur " d'abord, « un ami » par la suite " malgré la différence d'âge ${ }^{5}$ ». Après sa nomination en tant que directeur des Beaux-arts en 1919, Léon joua un rôle déterminant pour le démarrage de la carrière professionnelle de Hautecœur. Ce fut Léon qui le nomma enseignant, en remplacement d'André Pératé, et ensuite conservateur-adjoint, au Louvre (1920) ainsi que professeur d'histoire générale de l'architecture à l'École des Beaux-arts $(1925)^{6}$. De par ses fonctions au poste de directeur des Beaux-arts, dont il réactiva le pouvoir décisionnel et le poids politique ${ }^{7}$, Léon fut sans doute déjà un modèle pour Hautecœur lorsque ce dernier accepta, en 1927, d'être nommé directeur des Beaux-arts en Égypte sur les «vives instances » de Léon lui-même ${ }^{8}$. Sur les enjeux de cette nomination, fortement souhaitée non seulement par Léon mais aussi par le président du Crédit foncier égyptien, Émile Miriel ${ }^{9}$, Hautecœur s'exprimait à son tour 
au seuil des années 1960. Il rappelait "le plaisir» qu'il avait eu d'" accueillir en ce pays » le directeur des Beaux-arts de France, «lorsqu'il vint inaugurer l'Exposition française que j'avais organisée $»^{10}$, en l'accompagnant d'ailleurs durant sa visite en Égypte, du Caire jusqu'à Assouan. Si pour Hautecœur l'expérience égyptienne fut le précédent direct des fonctions assumées plus tard auprès du gouvernement de Vichy, elle se construisit sans doute en miroir par rapport aux attributions que recouvrait le poste occupé par Léon en France jusqu'en 1932 (Ill. 1).

«Le directeur des Beaux-arts - rappelait ce dernier en 1947 - est une sorte de touche-à-tout, un véritable Protée. Son domaine est fort étendu : théâtres, concerts, écoles, musées, achats et commandes, construction et restauration de bâtiments. Le programme d'action est immense. La réalité le dépasse. Solennités, commémorations, visites de souverains, autant de tâches qui lui incombent. De là beaucoup d'imprévu dans le cours même de la journée, l'ubiquité nécessaire, la décision immédiate, aucun temps pour faire oraison, l'appel impérieux de l'incident qui surgit au moment inattendu. Dans cette dissipation d'esprit, l'obligation de résoudre maintes questions techniques et financières ${ }^{11}$.»

III.1 : portrait de Paul Léon à son bureau

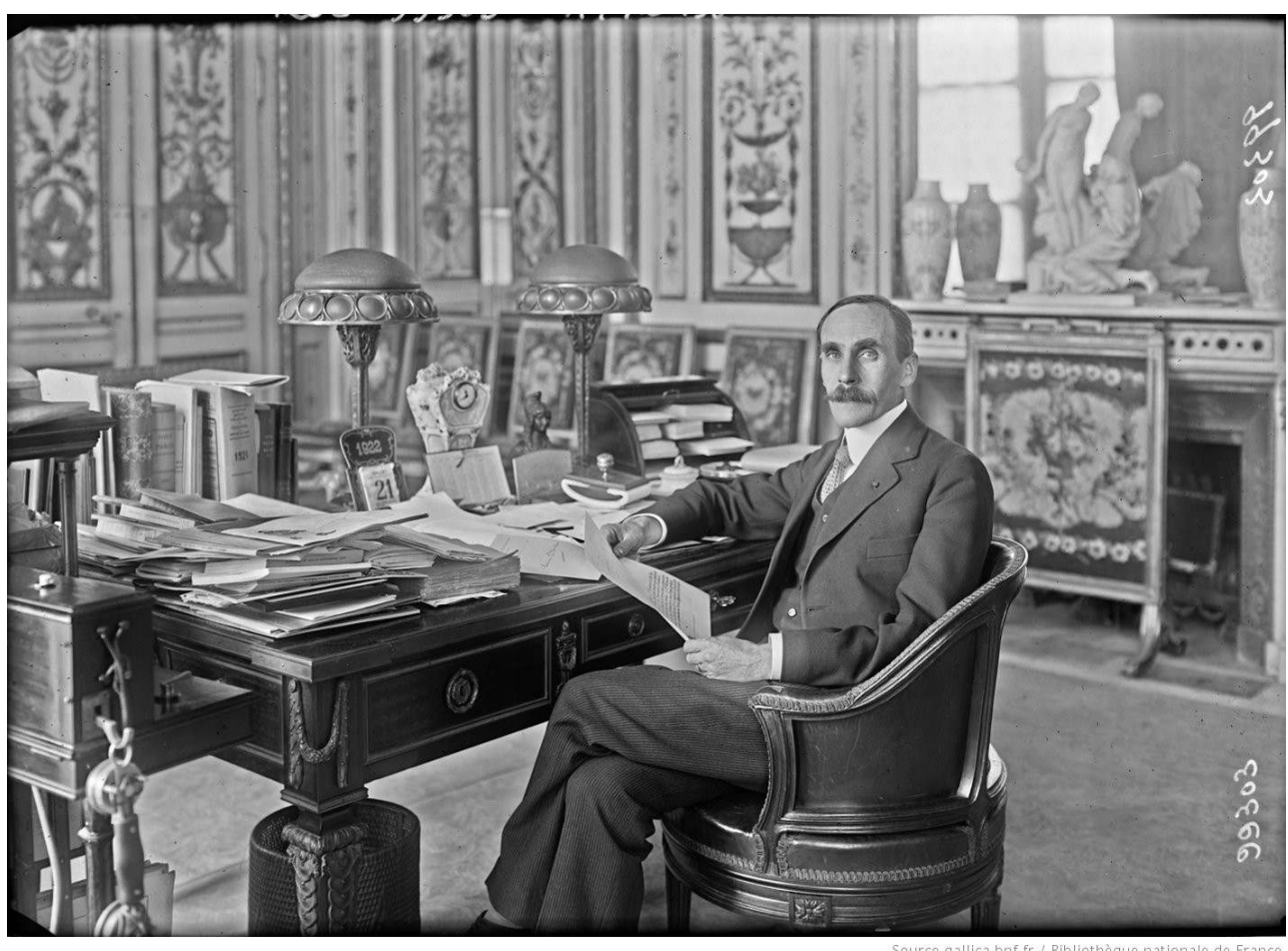

Photographie de presse, 1925, Agence Rol.

(c) Bibliothèque nationale de France, département des estampes et de la photographie, El-13 (1196), Rol, 99303.

2 Ce n'est pourtant pas à l'ensemble des actions de Léon que nous allons nous intéresser dans les pages qui suivent, mais surtout à la convergence qu'il instaura entre le domaine d'intervention concernant la protection du patrimoine et celui visant le projet d'architecture et ses acteurs ${ }^{12}$. Cette vision organique à propos de «construction et restauration de bâtiments", pour reprendre l'expression adoptée par Léon, joua un rôle majeur chez Hautecœur, et cela bien avant sa nomination à la direction et au secrétariat des Beaux-arts sous le régime de Vichy ${ }^{13}$. 


\section{Des enjeux historiographiques et éditoriaux partagés}

La rencontre intellectuelle entre les deux personnalités semble d'abord s'établir sur le terrain du mouvement de valorisation inédite du patrimoine architectural français des XVII et ${ }^{e}$ XVIII ${ }^{e}$ siècles, au lendemain de la Première Guerre mondiale. L'allocution de Léon à l'occasion de l'ouverture de l'exposition d'architecture française inaugurée à Strasbourg le 26 mai 1922 et reprise au début de l'année suivante au pavillon de Marsan à Paris, à l'organisation de laquelle Hautecœur participa activement ${ }^{14}$, est significative. Elle annonce la volonté d'articuler la mise en valeur et l'entretien du patrimoine architectural national avec la prise en compte des enjeux de l'architecture et de la ville contemporaines. Cette volonté de composition devint un fil conducteur, pendant l'entre-deux-guerres, des politiques menées par la direction des Beaux-arts: "Ces dessins, ces plans, ces tracés nous racontent comment la France, émancipée à la fin du XVII ${ }^{e}$ siècle de la tutelle italienne, institue et enseigne au monde les principes de la construction privée et de l'Architecture publique ${ }^{15}$ », proclamait Léon. Par l'évocation emphatique du « rayonnement » de l'art français, il pointait les caractères durables qui étaient censés représenter l'identité culturelle nationale : «la raison universelle de Descartes, le bon sens généralement accessible, l'équilibre entre les extrêmes, le don d'assimilation et surtout [...] le bon goût ${ }^{16}$.» Cela trahissait l'ambition de bâtir une vision historique cohérente de l'architecture française. Dès 1913, Léon avait mis en parallèle la «renaissance de l'architecture gothique» au fil du XIX ${ }^{\mathrm{e}}$ siècle et la "querelle des gothiques et des classiques" traversant l'histoire de l'art et de l'architecture français au même siècle ${ }^{17}$. Dix ans plus tard, alors que Léon livrait ses synthèses sur l'art roman et gothique français au sein d'une ambitieuse Encyclopédie des styles $^{18}$, Hautecœur contribuait, dès sa participation au XIII ${ }^{\mathrm{e}}$ congrès international d'histoire de l'art à Paris en 1921, à la définition du couple de catégories gothique/ classique en tant que pivot de l'architecture nationale et de sa généalogie ${ }^{19}$. Ébauché au début des années $1920^{20}$, le projet de publier une Histoire de l'architecture classique en France positionna Hautecœur dans la lignée des travaux de Robert de Lasteyrie sur l'architecture religieuse médiévale française, romane et gothique ${ }^{21}$. L'ouvrage que Léon fit paraître en 1951 sur la "vie des monuments français ${ }^{22}$ " fut conçu comme l'aboutissement du même dessein éditorial. À travers une synthèse historique concernant la pratique de la restauration monumentale en France depuis la période révolutionnaire, la contribution de Léon clôturait le cycle et situait dans une perspective unitaire les enjeux de la restauration du patrimoine national et l'ensemble de l'histoire de l'architecture française, du Moyen Âge aux Temps modernes ${ }^{23}$. Si cette perspective unitaire ne s'acheva, au point de vue éditorial, que dans les années 1950, elle se mit en place dès les années 1920 à travers l'évolution conjointe des enquêtes historiques et de la prise de conscience de la valeur patrimoniale des édifices concernés, d'abord par l'action de la Commission des monuments historiques. Dans ce contexte, la collaboration entre Léon et Hautecœur fut croissante durant les années 1920 et 1930, et fut marquée par le tournant de la conférence internationale d'Athènes en 1931, à laquelle ils participèrent tous les deux. L'attention accrue au patrimoine de l'« architecture classique » fut l'un des principaux axes de leur réflexion commune tout au long de l'entre-deux-guerres. 


\section{Élargir et protéger le corpus des monuments nationaux : une tâche fédératrice}

4 Le rôle incontournable de Léon au sein de la Commission des monuments historiques entre la seconde moitié des années 1910 et le seuil des années 1930 n'est plus à démontrer. Toujours présent aux séances de la Commission à partir de $1909^{24}$, il présida celle-ci de 1915 à 1932 et il favorisa le renforcement et l'élargissement de son action tout au long des années $1920^{25}$. Ce qui en revanche est très peu exploré et plus intéressant à éclairer de notre point de vue, est la proximité d'intérêts entre Léon et Hautecœur, qui se dégage assez tôt des mesures de protection et de restauration débattues au sein de la Commission, bien que Hautecœur ne l'ait intégrée comme membre de la première section qu'en $1932^{26}$. Il suffit de mentionner l'exemple de la restauration du château de Versailles, qui constitua un aspect fondamental du regard porté par Léon sur la restauration patrimoniale en France au lendemain de la Guerre ${ }^{27}$. Chargé de cours à l'École du Louvre depuis l'automne 1920, Hautecœur s'attacha, sur la voie tracée par Pierre de Nolhac, conservateur du musée de Versailles ${ }^{28}$, à l'histoire de l'architecture française entre la seconde moitié du XVII ${ }^{\mathrm{e}}$ et le début du XVIII ${ }^{\mathrm{e}}$ siècle jusqu'à faire de l'œuvre de Jules Hardouin-Mansart le sujet de son cours en $1924^{29}$. Léon intervint, quant à lui, en cette même année sur les questions de restauration du complexe monumental de Versailles, allant jusqu'à aborder les interventions dans le parc du château, au sujet desquelles il prit nettement position au sein de la Commission $^{30}$. Si Hautecœur souligna la place centrale de la contribution de Léon sur "la restauration des monuments en France» lors de la conférence internationale d'Athènes et réaffirma la nécessité de " poser des principes et d'examiner la méthode, comme le firent MM. Paul Léon, Giovannoni, Saintenoy, Torres-Balbas ${ }^{31} »$, la restauration du château de Versailles fut le cas d'étude porté en exemple par la section française à la conférence (Ill. 2). L'architecte Emmanuel Pontremoli, qui en faisait partie et qui avait dirigé cette restauration, présenta le château comme un véritable parangon " par sa complexité, par son ampleur et par le modèle qu'il fut des grandes résidences royales». Appartenant au domaine des "bâtiments civils et palais nationaux ", le château de Versailles fit l'objet d'une campagne de travaux pour laquelle les tenants de la protection des monuments historiques se mobilisèrent de manière exemplaire à partir du début des années $1920^{32}$. La portée idéologique de cette restauration pour la valorisation du patrimoine national de l'Ancien Régime demeura très forte, laissant son empreinte tout au long des années 1930. Léon insista encore, lors de son dernier cours au Collège de France en 1940, sur « les origines de l'architecture classique dont Versailles représente le type le plus parfait, par l'analyse d'édifices qui en constituent la préface ». Cela n'était pas en contradiction avec l'accent qu'il avait mis, dès le début de son enseignement au Collège en 1933, sur le cas de Reims, qui symbolisait, selon lui, le foyer de l'art national à la période gothique ${ }^{33}$. 


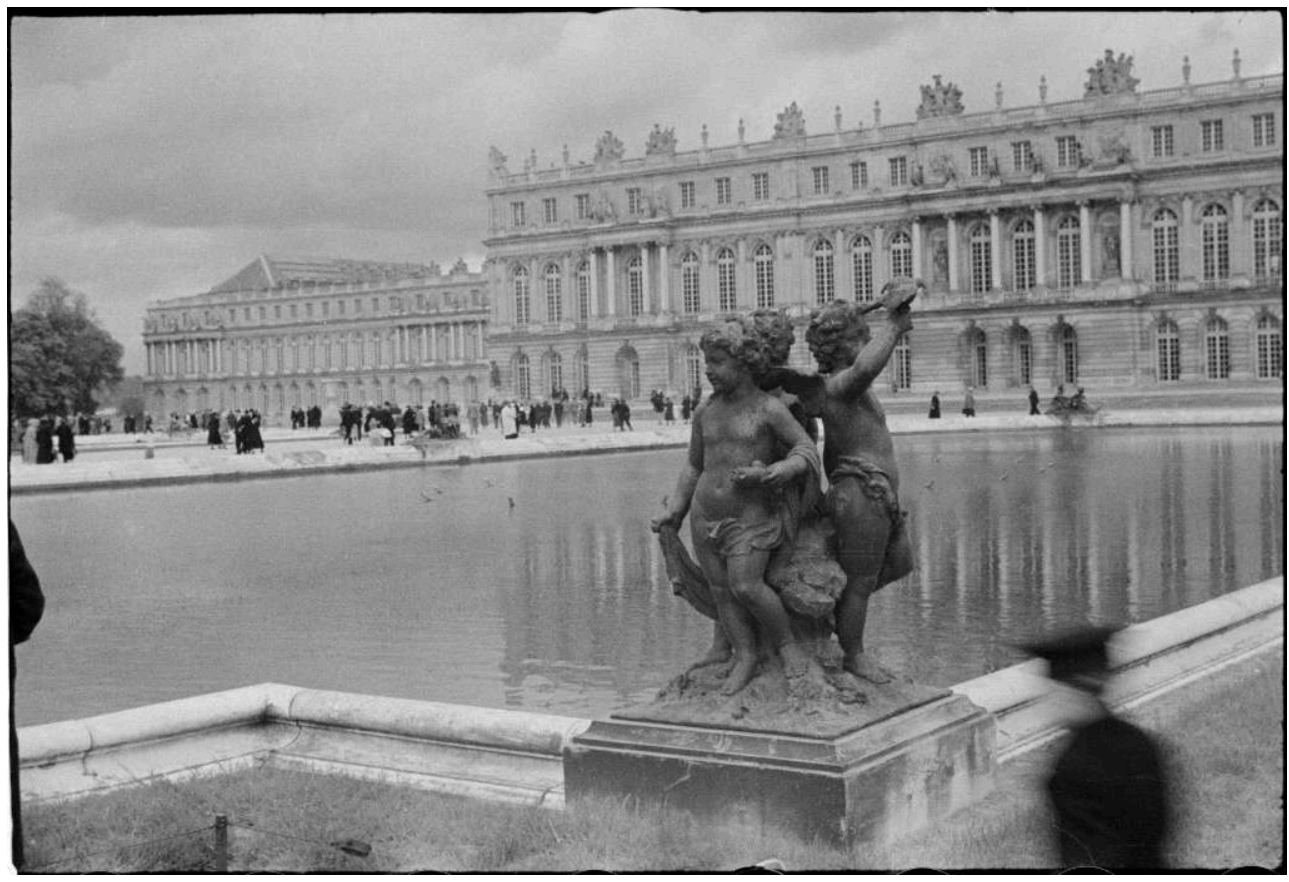

Années 1930

(c) RMN-Grand Palais - gestion droit d'auteur, André Kertész photo (c) Ministère de la Culture Médiathèque de l'architecture et du patrimoine, dist. RMN-Grand Palais / André Kertész

5 Bien avant qu'il n'intègre la première section de la Commission des monuments historiques, Hautecœur participa à l'évolution par laquelle, depuis le milieu des années 1920, la commission élargit de plus en plus la chronologie des édifices considérés dignes de mesures de protection, jusqu'à viser des spécimens de l'architecture du XIX siècle, tels que le théâtre de l'Opéra et ses abords, ou la cour d'honneur du palais des Études de l'École des Beaux-arts ${ }^{34}$. Les dates de commande et de parution des deux chapitres pour l'Histoire de l'art dirigée par André Michel que Hautecœur consacra à l'architecture du XIX ${ }^{\mathrm{e}}$ siècle " jusqu'à nos jours $»^{35}$, montrent à quel point l'hybridation d'idées et de compétences entre le milieu des historiens de l'art et celui des membres de la commission était active à cette époque. Par ailleurs, autour de cette même année 1933 alors que Léon venait de quitter la direction des Beaux-arts et démarrait ses cours au Collège de France, le nom de Hautecœur est sans doute à mettre en lien avec quelques épisodes notables concernant la valorisation et la protection d'exemples remarquables d'architecture de la période moderne par la Commission des monuments historiques. Dès la fin de 1932, Hautecœur fut toujours présent aux séances de la Commission à l'occasion de débats importants sur la préservation d'édifices des XVII ${ }^{e}$ et XVIII ${ }^{e}$ siècles. Ce fut le cas, le 17 décembre 1932, pour la proposition de classement général du complexe monumental des Invalides, ainsi que lors de la discussion sur le projet de restauration de la place de la Bourse de Bordeaux $^{36}$. La veille, Hautecœur avait participé au débat sur la proposition de classement des remparts de Vauban à Besançon. Les pourparlers avec la municipalité pour contenir les projets de démolition furent le but de l'envoi sur place d'une délégation de la Commission, dont Hautecœur fit probablement partie ${ }^{37}$. Il n'est pas difficile d'imaginer son rôle dans la décision, arrêtée le 27 janvier 1933, de demander à la Commission supérieure des Sites d'inscrire dans son inventaire le rempart d'Arènes, 
les bastions Vieil Picard, Charmont et Battant, et le Fort Griffon. Le troisième centenaire de la naissance de Vauban fut l'occasion afin d'en réaliser une publication, d'initier l'«exécution de relevés accompagnés de photographies de toutes les fortifications de Vauban subsistant en France ${ }^{38}$.

Cinq ans plus tard, lorsque s'imposa l'urgence de renforcer le corps des architectes en chef des Monuments historiques, tombé de quarante à trente - le dernier concours remontait à 1925 - Hautecœur fut nommé, le 21 décembre 1938, membre du jury du nouveau concours pour dix postes d'architecte en chef, en remplacement de Gabriel Faure, aux côtés, entre autres, de Paul Verdier, Jean Verrier, Marcel Aubert, anciens délégués de la conférences d'Athènes, mais aussi des architectes Patrice Bonnet et Jules Formigée ${ }^{39}$. Cette nomination révèle l'autorité qu'il avait acquise, à la fin des années 1930, dans le domaine de la protection des monuments, dans le cadre d'une stratégie d'action multiple.

\section{Passé et présent de l'architecture française : un horizon commun}

7 Ce serait pourtant diminuer le retentissement de l'action de Léon sur les orientations développées par Hautecœur que de limiter sa lecture au domaine de la protection des monuments. Le ralliement, dès les années précédant le premier conflit mondial des acquis de la sauvegarde et de la restauration des bâtiments historiques à la perspective, plus large, de la gestion des bâtiments civils, fut le legs principal de l'action menée par Léon. Arlette Auduc a montré comment, à travers la création, par la loi du 15 juillet 1907, de la division des services d'architecture à la tête de laquelle Léon fut aussitôt nommé, le service des monuments historiques fut amené à composer avec celui des bâtiments civils, dans une volonté d'harmonisation dont l'impact atteignit même le projet de restauration du château de Versailles, qui faisait déjà l'objet de discussions à l'époque ${ }^{40}$.

8 De plus, la guerre et les problématiques liées à la reconstruction consolidèrent et catalysèrent cette vision convergente des questions d'intervention sur le patrimoine et d'attention à la conception contemporaine. Or, parmi les premières entrevues qu'Hautecœur mentionnait dans son agenda au lendemain de sa nomination à la Direction générale des Beaux-arts, il était question de réunions avec Léon, rencontré plusieurs fois entre juillet et septembre $1940^{41}$ et sans doute même après, à Royat, où l'ancien directeur des Beaux-arts s'était réfugié après l'occupation allemande ${ }^{42}$. Il n'est pas anodin que le sujet qu'Hautecœur aborda avec lui fut précisément la reconstruction. Ce ne l'est pas non plus qu'un an et demi plus tard, il n'hésite pas à solliciter des dérogations pour Léon, frappé par les lois de discrimination raciale promulguées par le régime vichyste au printemps 1941, et à recommander l'ancien directeur des Beaux-arts, dont il évoque les activités, les charges assumées, les publications et les projets afin de témoigner de son dévouement à la nation et de souligner combien son œuvre avait accompagné le parcours professionnel de Hautecœur depuis l'entre-deux-guerres ${ }^{43}$.

9 Pour Hautecœur, l'apport de Léon n'était pas exclusivement lié à la restauration patrimoniale. Cela apparaît à travers les pages du bilan qu'il publia en 1948 sur les Beaux-arts en France entre passé et avenir. Dans ces mémoires, il loua l'effort de 
coordination sur le terrain de l'architecture civile poursuivi par Léon, «lorsqu'il avait créé la division de l'architecture, supprimée lorsqu'il fut nommé Directeur général des Beaux-arts $»^{44}$. C'était donc par l'action en ce domaine qu'Hautecœur revendiquait, encore à la fin de la Seconde Guerre mondiale, la plus forte continuité :

«J'estimai nécessaire de rétablir et de compléter cette organisation. L'importance des travaux exécutés, des crédits alloués, le nombre des architectes, fonctionnaires, contrôleurs, vérificateurs, entrepreneurs, ouvriers, jardiniers, gardiens, surveillants, justifiaient une telle mesure ${ }^{45}$. 》

La création d'une direction des services d'architecture auprès de la Direction générale des Beaux-arts par la loi du $1^{\text {er }}$ décembre 1940, comme la désignation, à la tête de ces services, de René Perchet ${ }^{46}$ "qu'avait distingué $\mathrm{M}$. Paul Léon et que j'avais connu à l'Exposition de 1937 », se plaçaient donc dans la continuité de l'action de son illustre prédécesseur ${ }^{47}$. Perchet avait occupé, en fait, le poste de rédacteur au sein du bureau des Bâtiments Civils dès 1921, au lendemain de la nomination de Léon à la direction des Beaux-arts. Lui, comme d'autres personnalités-clés liées aux nouveaux services mis en place par Hautecœur, étaient, au-delà même de son témoignage, la manifestation tangible de l'héritage de Léon. La "défense de la beauté française ", dont Hautecœur plaidait la cause en 1943 , se concrétisa d'ailleurs par une série de nouvelles lois $^{48}$ prolongeant les enjeux de la loi du 2 mai 1930 qui avait eu « pour objet de réorganiser la protection des monuments naturels et des sites de caractère artistique, historique, scientifique, légendaire ou pittoresque ${ }^{49}$ ". S'il fallait encore une preuve des continuités entre les actions administratives de l'un et de l'autre, le fait que Léon ait conservé, après la seconde guerre, un rapport détaillé sur l'activité législative de la direction et du secrétariat des Beaux-arts entre l'été 1940 et le printemps $1944^{50}$, n'est certes pas anodin. L'argument de la prédominance de l'action administrative sur les orientations politiques était d'ailleurs mis en avant par l'un comme par l'autre. Ainsi Léon affirmaitil en 1947 :

« Un changement de ministère est une opération saisonnière [...]. De 1905 à 1938, comme fonctionnaire des Beaux-arts ou comme commissaire d'Exposition, j'en ai servi cinquante-huit. Le changement est souvent plus apparent que réel. On reprend les mêmes, mais pas au même poste. L'acteur reste, son rôle varie [...]. L'essentiel n'est pas d'être au pouvoir, mais d'y avoir été ${ }^{51}$. "

Hautecœur, de son côté, affirmait un an plus tard, au sujet de sa nomination par le gouvernement de Vichy :

«La question politique ne se posait pas pour moi. Fonctionnaire, j'avais vu se succéder des ministères de toutes les couleurs. J'appartenais depuis plus de vingt ans à une administration dont j'étais l'un des doyens et dont j'avais gravi les échelons. [...] Le Ministère me faisait l'honneur de me confier des fonctions administratives qui n'avaient aucun caractère politique ${ }^{52}$. »

12 Il n'en demeure pas moins que les conjonctures étaient bien plus complexes, que les enjeux n'étaient pas limités aux compétences mûries dans les rouages de l'administration d'État et que la solution de continuité, éminemment politique, entre la nomination de Hautecœur en juillet 1940 et le mandat de son prédécesseur à la direction des Beaux-arts, Georges Huisman ${ }^{53}$, est évidente. Également évidente est la solution de continuité entre le cadre politique à travers lequel Léon évolua pendant treize ans à la tête des Beaux-arts, et le milieu d'où son successeur, Émile Bollaert, ensuite remplacé par Huisman ${ }^{54}$, était issu, qui était profondément lié à Édouard Herriot, président du parti radical et chef de file du Cartel des gauches ${ }^{55}$. 
13 Certes, le modèle que constituait l'administration des Beaux-arts sous la conduite de Léon, fut indéniable. La «longévité administrative » de Léon ${ }^{56}$, rappelée par l'historien d'art Georges Wildenstein, au lendemain de sa disparition, trouvait ses origines bien en amont de sa nomination à la direction des Beaux-arts, tout en se consolidant au sortir de la Grande Guerre. Sans doute aussitôt remarqué par Hautecœur qui avait fait la connaissance de Léon dès $1916^{57}$, l'ouvrage La guerre et l'architecture. La Renaissance des ruines; maisons, monuments que ce dernier publia en 1918 est l'expression éloquente de son regard simultané sur la restauration patrimoniale et la reconstruction architecturale à l'heure des destructions provoquées par le premier conflit mondial ${ }^{58}$. Il s'agit d'une position qui trouve son origine une dizaine d'années auparavant, lorsque Paul Léon fut nommé chef des services d'architecture à la Sous-direction des Beauxarts. Si dans cet ouvrage, il aborde la question de « la reconstitution monumentale de la France ${ }^{59}$ ", cela fait suite à un chapitre entier consacré au "projet pour la reconstruction des habitations rurales ", ce dernier étant lui-même précédé par le texte de la conférence qu'il avait donnée un an plus tôt, dans le cadre de l'exposition sur l'architecture régionale dans les provinces envahies, présentée du 10 janvier au 10 février 1917 au pavillon de Marsan ${ }^{60}$. Léon partageait les initiatives prises en ce domaine par la Société des architectes diplômés par le gouvernement (SADG) et parrainées par son président de l'époque, l'architecte André Hermant. Un témoignage éloquent de l'influence de ce double regard de Léon nous est donné par Hautecœur. Devenu en 1922 rédacteur en chef de la revue de la Société centrale des architectes, L'Architecture ${ }^{61}$, ce dernier y publia tout d'abord un article sur la construction de logements de cités ouvrières dans le Nord, le Loiret ou la Marne ${ }^{62}$, tandis qu'il prit parallèlement l'initiative d'accueillir dans les pages de la revue une contribution du secrétaire de la commission des Monuments historiques, Pierre Schommer, à propos de la reconstruction des maisons de la Grande et de la Petite place d'Arras ${ }^{63}$. Par ailleurs l'approche régionaliste à travers laquelle Léon s'intéressa, pendant la seconde moitié des années 1910, à la reconstruction de l'architecture domestique, notamment en milieu rural, peut sous de nombreux aspects être mise en relation avec les positionnements qu'Hautecœur adopta à son tour lors de la Seconde Guerre mondiale, lorsqu'il plaida pour une architecture «à la fois régionale et nationale, traditionnelle et moderne $~{ }^{64}$, jusqu'à demander ouvertement, au lendemain de la guerre, d' "harmonis[er] nos maisons avec le paysage " ${ }^{65}$. C'est cependant dans le domaine de l'architecture religieuse, objet de lourdes destructions ${ }^{66}$, que Léon invitait en 1918 à dépasser les historicismes du XIX ${ }^{e}$ siècle. Il s'agissait pour lui de dialoguer avec les moyens constructifs les plus novateurs et d'envisager les solutions typologiques les plus originales. Le portrait d'édifice religieux du futur qu'il brossait paraît anticiper et devancer le type d'espace et de structure que les frères Perret conçurent, quatre ans plus tard, avec la réalisation de Notre-Dame du Raincy (1922-1923) ${ }^{67}$. Ainsi parmi les "faits actuels [qui] dominent nécessairement la conception de ces vastes salles d'assemblée que sont aujourd'hui les églises ", Léon pointait «d'abord la possibilité de couvrir de grandes portées sans points d'appui intermédiaires », et en interrogeait les conséquences:

"Suppression des bas-côtés, création d'une nef unique, [...] disparition de l'étaiement extérieur que constitue l'arc-boutant ? Ne voyons point dans ces possibilités de changements la fin de l'architecture chrétienne. Les ponts à piles de pierre n'ont-ils pas fait place aux ponts métalliques d'une seule volée dont nous admirons la hardiesse et la surprenante beauté ? Et n'était-ce pas déjà la constante préoccupation des maîtres d'œuvre gothiques que de diminuer la matière inerte, de 
réduire les points d'appui, d'ouvrir de larges espaces aux colorations de la lumière ${ }^{68}$ ?"

14 Une quinzaine d'années plus tard, au début de l'activité d'enseignement de Léon au Collège de France, ses cours dans lesquels il accordait pourtant une place fondamentale à l'architecture et à la ville des XVII ${ }^{\mathrm{e}}$ et XVIII ${ }^{\mathrm{e}}$ siècles, aux pratiques de la conservation et aux doctrines de la restauration élaborées en France à partir des principes définis par Viollet-le-Duc, n'éclipsèrent pas les problématiques plus directement liées à l'architecture contemporaine. Après avoir coopéré une première fois avec la SADG lors de l'exposition d'architecture régionaliste de 1917, Léon intervint devant son auditoire du Collège de France au sujet de l'exposition consacrée à l'architecture française contemporaine que la même SADG avait organisé en 1933. Non seulement Hautecœur mit en avant cette exposition dans les pages de la revue L'Architecture (Ill. 3) ; mais encore, il contribua lui-même à son idéation et à sa circulation internationale jusqu'au seuil des années $1940^{69}$. Or, en dressant, pour son cours du 8 mai 1934, un «état des lieux de l'architecture » qui l'amenait à questionner en profondeur le devenir de la profession d'architecte, Léon s'était lui-même prononcé sur cette exposition, en en tirant un bilan très net et positif :

« Il y a peu de temps [...] j'admirais une exposition d'œuvres actuelles dont la vue donnait aux critiques une réponse péremptoire. Je pense qu'il n'est pas un pays qui puisse s'enorgueillir d'une plus belle sélection : monuments édifiés dans les régions dévastées, églises, hôtels de ville, palais de justice ; organisation urbaine, édilitaire, administrative de nos colonies; adaptation à la découverte scientifique et à la technique industrielle : garages, hangars, aéroports ; établissements d'hygiène et d'utilité sociale : sanatoria, piscines, stades, écoles, postes, banques, halles, ponts, théâtres, fermes, manufactures, cités-jardins. Diversité des programmes, diversité des talents, rapprochés cependant par une parenté de style et d'époque, par une forte alliance de tradition et de modernisme. C'était là une grande leçon qui se passait de commentaires. L'architecture française est aussi vivante, aussi riche de sève, aussi ferme en ses principes, aussi souple en ses solutions qu'elle le fut à aucune époque. Son lendemain est [sic] paraît assuré ${ }^{70}$.» 


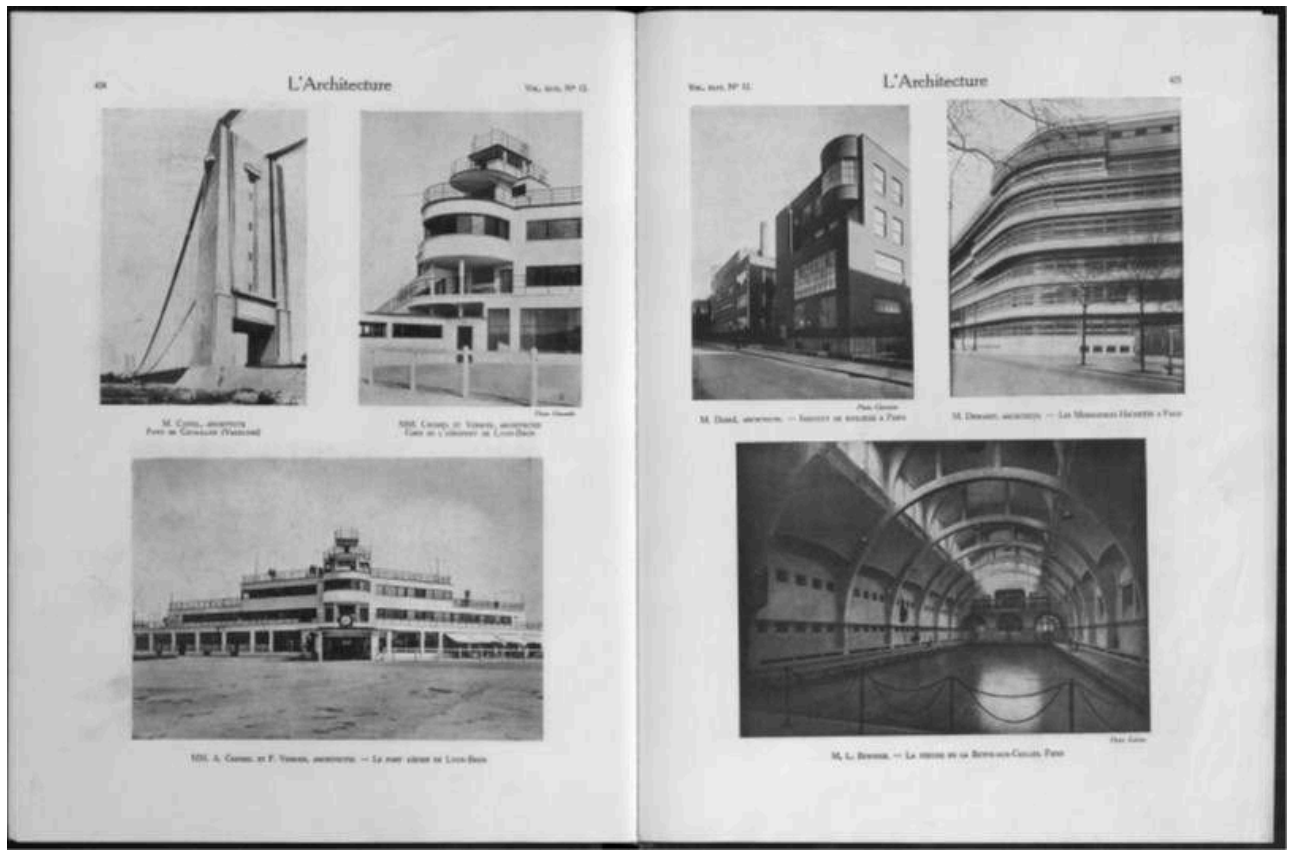

Sous le patronage de l'Association française d'expansion et d'échanges artistiques.

(c) L'Architecture, XLVI, nº 12, 15 décembre 1933, p. 424-425.

Le raturage du verbe "est» n'est pas anodin, car Léon montrait une connaissance précise de la « crise » que l'architecture traversait à l'époque, crise dont de nombreux précédents étaient en tout cas détectables, selon lui, au fil de l'histoire ${ }^{71}$. Si Léon, comme Hautecœur, n'était pas architecte, il affichait néanmoins sa proximité avec le milieu architectural à la lumière de son parcours professionnel ${ }^{72}$ et de sa défense de l'héritage des grands archétypes de l'architecture française «classique ", sous le signe de la continuité entre passé et présent. Il précisait ainsi :

«Je me suis dit qu'au surplus, si je n'étais pas architecte, j'avais été du moins, pendant près de trente années [...] le premier gérant d'immeubles de France, d'immeubles tels que le Louvre, Versailles ou Fontainebleau, immeubles dont le rapport se compte en histoire et en gloire. Pendant ces longues années je crois avoir appris à connaître les architectes; je les ai vu très attaqués, mal défendus, incapables de polémique, laissant courir bien des erreurs faute de temps pour les rectifier, répondant aux critiques par des œuvres selon le précepte de Philibert Delorme [sic] qui commande à l'architecte de se garder de trop parler car il est meilleur de bien faire ${ }^{73}$. "

En fait, l'attention portée par Léon à l'actualité architecturale se développait à la lumière d'un regard sur l'histoire de l'architecture remontant jusqu'au XVI ${ }^{\mathrm{e}}$ siècle, voire au Moyen Âge - en songeant à un «modernisme médiéval» auquel correspondrait un "modernisme d'aujourd'hui»-, par l'emploi de couples de catégories antagonistes et pourtant complémentaires, tels que "tradition-évolution » ou «érudition-création $»^{74}$. "En architecture - affirmait-il - moins qu'ailleurs on ne peut s'abstraire du passé. Les morts comptent plus que les vivants. [...] L'histoire de l'architecture hante la pensée de l'architecte $»^{75}$. Or, dès la préface du catalogue de l'exposition d'architecture des XVII ${ }^{e}$ et XVIII ${ }^{e}$ siècles en 1922, Hautecœur avait énoncé cette connexion entre le passé de l'architecture française et son actualité. Le double enseignement que Hautecœur dégageait des dessins exposés, à savoir «quelle fut la 
tradition française et quels sont les traits du caractère national », passait par le constat de caractères culturels et anthropologiques permanents: "L'architecture d'un peuple est l'expression de son tempérament, de ses habitudes; elle Lui est imposée par le climat de son pays, les matériaux dont il dispose ; elle suit les progrès de la science ${ }^{76}$. En 1922 l'allusion à un projet ultérieur d'exposition, par lequel les organisateurs se proposaient de "grouper les œuvres des architectes français contemporains", était significative: on envisageait ainsi d'illustrer leur cohérence avec l'héritage historique de l'architecture française dans la composition et la construction. Dix ans plus tard, en 1933, l'exposition réalisée par la SADG à Paris, appréciée par Léon et portée par Hautecœur, se donnait l'objectif de montrer comment l'architecture en France, tout en étant «moderne", «reste cependant soumise à des traditions $»^{77}$. Ces traditions n'étaient pas assimilables à une simple imitation ou répétition de formes comme le soulignait Hautecœur dans la préface du catalogue de cette nouvelle exposition : «la tradition, c'est l'ensemble des qualités imposées par l'esprit, le climat, les habitudes sociales d'un pays ». C'est ainsi, selon lui, que cette tradition pouvait atteindre un caractère intemporel ${ }^{78}$.

\section{Un banc d'essai : les expositions internationales, « encyclopédie concrète "}

17 L'investissement de Léon, depuis la veille de la Première Guerre mondiale, dans l'organisation de l'Exposition internationale des arts décoratifs et industriels modernes qui eut finalement lieu en $1925^{79}$ (Ill.4), pour laquelle il avait nommé Hautecœur « membre de la classe I (Architecture) » du comité d'admission ${ }^{80}$, est assez parlant pour définir les contours d'une notion d'" architecture moderne" à laquelle les deux hommes adhérèrent de manière comparable. S'occupant lui-même de la présentation du rapport général de cette exposition, paru en 1931 ${ }^{81}$, Léon pouvait évoquer en 1934 «l'Exposition de 1925 et ses lendemains» comme le contexte dans lequel «s'était affirmée [...] l'architecture moderne, liant structure et décor, harmonisant les façades et les plans, les matériaux et les formes $~_{82}$, tout en ne prenant sans doute pas parti pour l'idée de modernité qu'affichaient les projets architecturaux et urbains d'un Le Corbusier ${ }^{33}$. En cette même année 1934, l'aventure d'une nouvelle exposition internationale venait de démarrer ${ }^{84}$. La promotion des « arts et techniques dans la vie moderne " portée par l'exposition de 1937 fut à nouveau un terrain de rencontres entre les deux hommes. Conseiller technique de l'exposition depuis le 31 juillet 1934, avant d'être nommé deux ans plus tard à la direction des travaux d'art, le 28 juin 1935, Hautecœur fut appelé à représenter le commissaire général adjoint, Léon, par décision du commissaire général de l'exposition Edmond Labbé. Avec Léon, il apporta son soutien à quelques-unes des collaborations les plus innovantes entre architectes et artistes, comme celle du pavillon de l'Électricité et de la Lumière. Pour celui-ci il joua un rôle au sein du comité spécialement préposé à la sélection des vitraux pour la façade ${ }^{85}$, alors que Léon rédigea la préface du catalogue de ces vitraux établi par l'architecte du pavillon, Robert Mallet-Steven ${ }^{86}$. Président du Comité de l'électricité, Léon saisissait la relation étroite entre celle-ci et l'architecture et même la ville contemporaines $^{87}$. Plus largement encore, il saisissait l'intérêt de tous les moyens permettant d'inscrire l'architecture dans un plus vaste mouvement de modernisation, comme dans le cas de la cinématographie ${ }^{88}$. Le débat autour du projet du Centre 
régional de l'exposition fut d'ailleurs une évidente occasion de confrontation entre Hautecœur, qui en revendiquait même l'idée de la conception, et Léon, avec lequel il en discuta et se mesura autour de l'objectif de «montrer comment il était possible dans nos provinces d'adapter les matériaux, les formes locales aux besoins, aux procédés nouveaux ${ }^{89}$ ». Pour l'ancien directeur des Beaux-arts, cela n'entrait pas en contradiction avec les principes de la conservation des monuments qu'il venait de défendre à Athènes, une position sans doute assumée par Hautecœur. Léon affirmait ainsi en 1931 :

«C'est un singulier paradoxe que l'architecture moderne, rompant nettement, par l'universel emploi des matériaux moulés et plaqués avec l'antique et traditionnelle construction par assise et refouillement, ait si puissamment aidé à la conservation de nos monuments anciens, auxquels elle est, dans son principe, radicalement étrangère et qu'elle est, dans l'avenir, destinée à remplacer. [...] Aujourd'hui c'en est fini de la querelle des anciens et des modernes, de la proscription ou de l'idolâtrie des styles. La scrupuleuse conservation de tous les arts du passé s'allie à la liberté des recherches du présent ${ }^{90}$.»

III. 4 : construction des bâtiments pour l'exposition internationale des arts décoratifs et industriels modernes

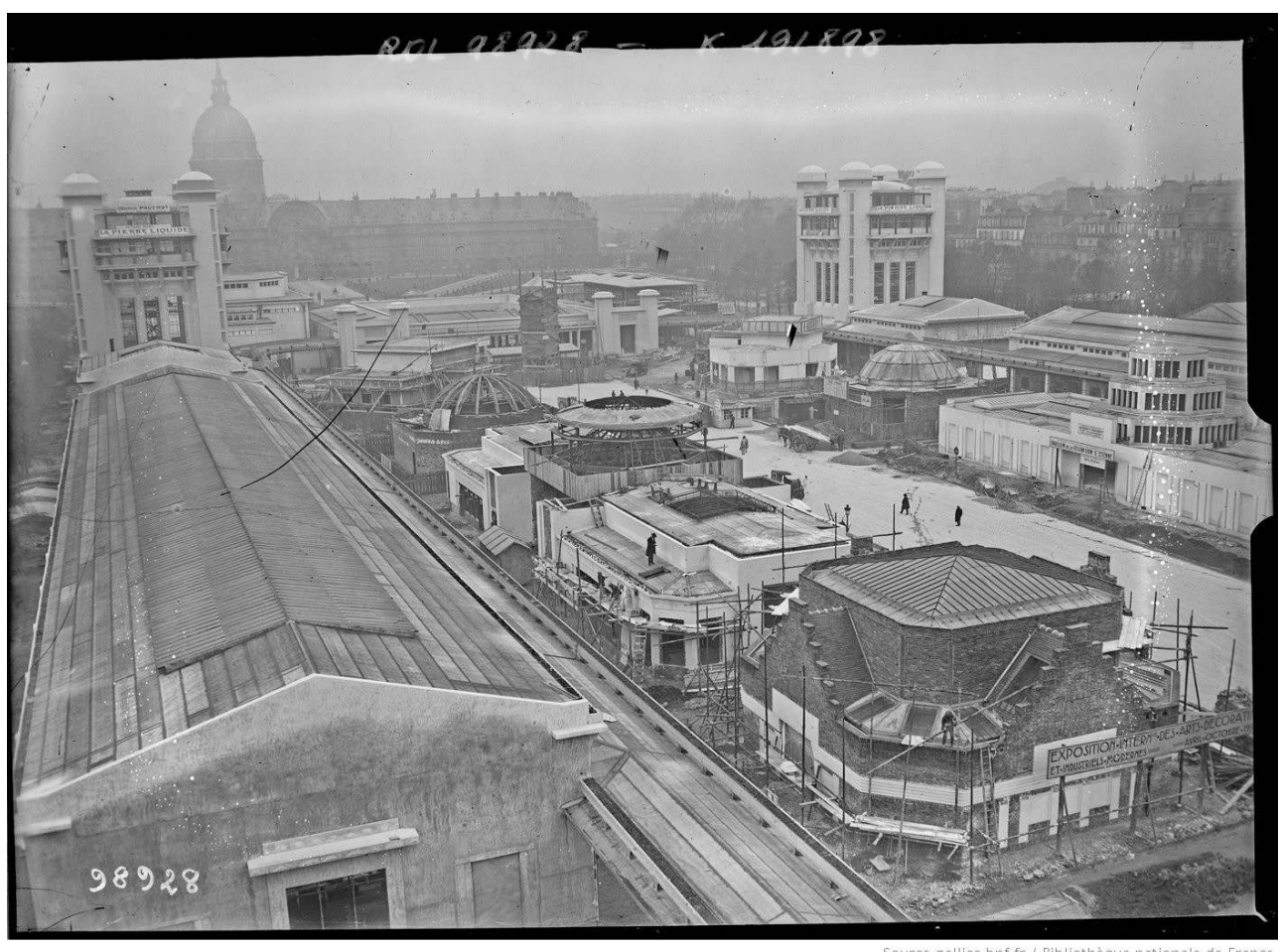

Photographie de presse, 4 mars 1925, Agence Rol.

(C) Bibliothèque nationale de France, Département des estampes et de la photographie, El-13 (1191), Rol 98928

L'esprit moderne dans les arts décoratifs et industriels que l'Exposition de 1925 avait illustré, reposait aux yeux de Léon sur la relation incontournable entre hier et aujourd'hui :

« renouer avec la tradition par tout ce qu'elle a de logique, - lit-on dans le texte introductif du premier tome du rapport publié en cette même année 1931 - trouver dans la destination des objets et dans les moyens techniques de les réaliser une expression neuve qui ne soit ni la contradiction ni l'imitation de formes 
antérieures, mais en constitue la suite naturelle, tel est l'idéal moderne du

$\mathrm{XX}^{\mathrm{e}}$ siècle $^{91}$.»

19 Ainsi, six ans plus tard Léon adhérait-il à la célébration des «styles » légués par les époques précédentes à l'occasion de l'Exposition internationale des arts et des techniques, en l'occurrence dans le domaine de l'ameublement (Ill.5) ; il affirmait qu'« il en est de l'histoire des arts appliqués comme de celle des idées et des mœurs : en se pénétrant des leçons du passé, on comprend mieux le présent, on conçoit mieux l'avenir $»^{92}$.

III. 5 : Albert Keim, Les styles. L'art ancien dans l'ameublement...

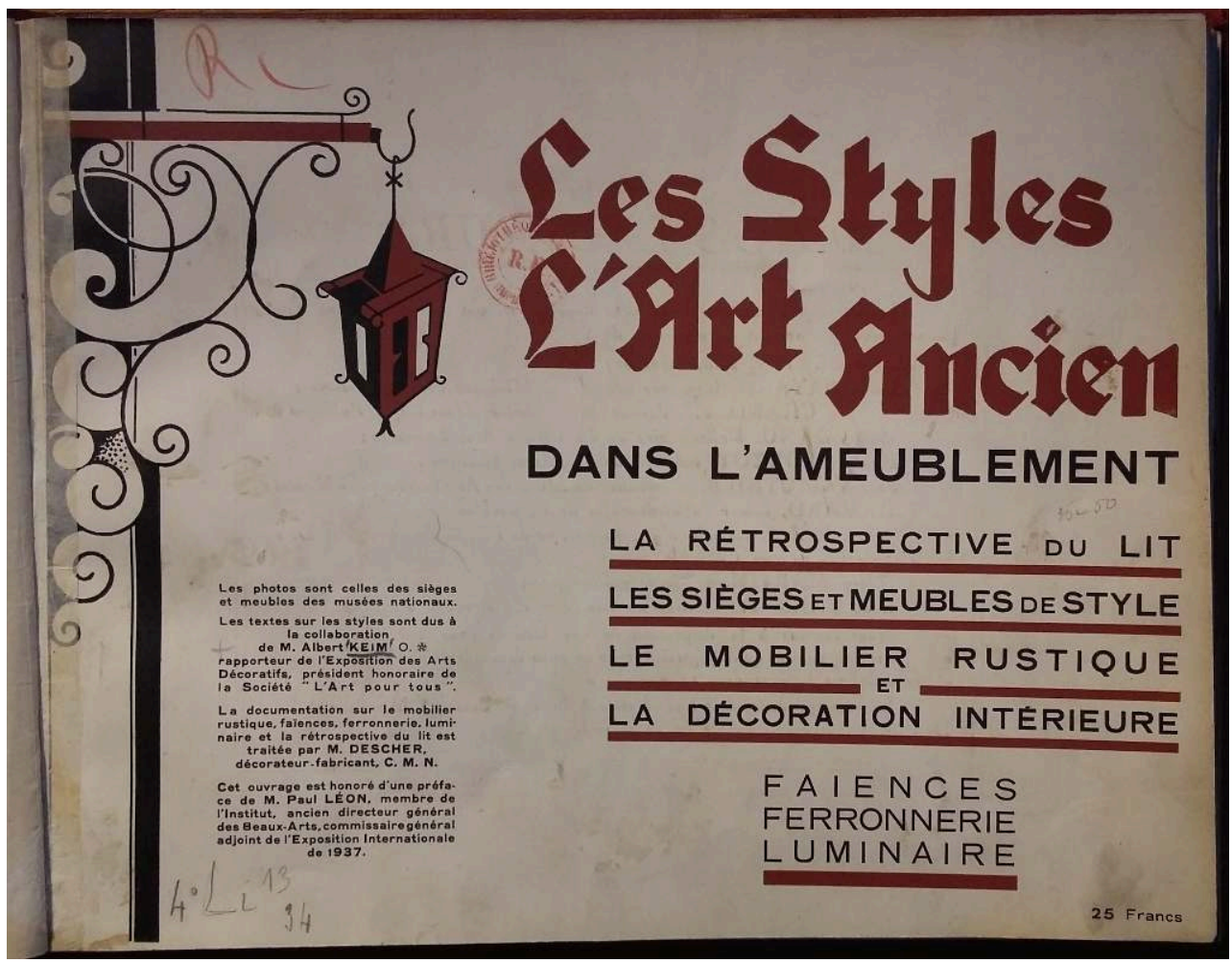

Les styles. L'art ancien dans l'ameublement. La rétrospective du lit, les sièges et meubles de styles, le mobilier rustique et la décoration intérieure. Faïences, ferronnerie, luminaire, Clermont-Ferrand, Société Mont-Louis, 1937, frontispice.

D. R.

Sans doute cette attention à la vaste palette de la production artistique, technique et scientifique que les expositions universelles réunissaient depuis la seconde moitié du $\mathrm{XIX}^{\mathrm{e}}$ siècle, fut un dénominateur commun essentiel chez Léon et Hautecœur, tout à fait représentatif - l'un des points forts même - de l'ensemble des tâches multiples auxquelles le directeur, puis ancien directeur, des Beaux-arts se mesura pendant l'entre-deux-guerres. Le fait que Léon manifestât encore, en 1939, tout son intérêt pour la section française de l'Exposition internationale qui eut lieu à New York ${ }^{93}$, n'est pas anodin. Pour sa part, Hautecœur saisit tout au moins la quintessence d'un phénomène en prise directe avec la contemporanéité :

«Les expositions ne laissent pas seulement des édifices, mais aussi des exemples.

Une exposition c'est une sorte de bilan de la civilisation présente, c'est une Encyclopédie concrète, c'est un moyen de comparer des disciplines différentes, une sorte de catalyseur des idées flottantes ${ }^{94}$.» 
La participation à l'organisation de ces expositions internationales de l'entre-deuxguerres s'avère sans doute l'un des terrains les plus éloquents du partage par Léon et Hautecœur d'une vision très proche du devenir du patrimoine et de l'architecture et d'une interprétation concordante de l'évolution des arts vis-à-vis de l'innovation technologique. Il fut question d'un partage scellé par leur manière commune d'entendre l'articulation des temporalités des productions artistiques nationales. Surtout, ce fut un partage scellé par une même conception des prérogatives, des tâches et des stratégies propres à l'administration des Beaux-arts sous la Troisième République.

\section{NOTES}

1. Vingt-huit lettres et cartes envoyées par Paul Léon depuis l'entre-deux-guerres, et dix-neuf lettres de son fils Jean-Paul. Voir l'inventaire de la correspondance personnelle de Hautecœur, sous scellé jusqu'en 2023, dans A. Brucculeri, Du dessein historique à l'architecture publique. Louis Hautecoeur et l'architecture classique en France, Paris, Picard, 2007, p. 403.

2. Médiathèque de l'architecture et du patrimoine (MAP), fonds Paul Léon, carton 0080/047/005, brouillon manuscrit du compte-rendu (1954) de l'ouvrage de Hautecœur : Mystique et architecture. Symbolisme du cercle et de la coupole, Paris, Picard et $\mathrm{C}^{\mathrm{ie}}$, 1954, lu par Léon à l'assemblée des membres de l'Académie des Beaux-arts.

3. L. Hautecœur, « Notices sur les membres décédés : Léon (Paul) », Association amicale des anciens élèves de l'École normale supérieure, 1963, p. 28-31.

4. Léon intégra l'École normale supérieure en 1894, Hautecœur en 1905. Sur le milieu de l'École, cf. Robert J. Smith, The Ecole Normale Supérieure and the IIIrd Republic, New York, State University of New York Press, 1982 et Jean-François Sirinelli (dir.), L'École normale supérieure. Le livre du bicentenaire, Paris, PUF, 1994.

5. Nous rappelons que Paul Léon était né le 2 octobre 1874 et Louis Hautecœur le 11 juin 1884. Cf. L. Hautecœur, Notices sur les membres décédés : Léon (Paul)... op. cit., p. 28.

6. Sur les débuts de la carrière professionnelle de Hautecœur, nous renvoyons aux repères biographiques dans A. Brucculeri, Du dessein historique à l'action publique... op. cit., notamment p. 391-393.

7. Voir Marie-Claude Genet-Delacroix, Art et État sous la III République. Le système des Beaux-arts 1870-1940, Paris, Publications de la Sorbonne, 1992, et Ead., « Histoire et fonction de la direction des Beaux-arts (1870-1905) », Romantisme, 1996, n 93, p. 39-50.

8. Le $1^{\text {er }}$ décembre 1927 il fut nommé par arrêté du ministre de l'Éducation nationale, Édouard Herriot. « Mon ami Louis Hautecœur était alors directeur des Beaux-arts en Égypte - évoque Léon dans ses mémoires parues en 1947, à propos de son voyage au Caire en 1929 -. C'est sur mes vives instances qu'il avait accepté ce poste, important pour l'influence française » ajoute-t-il. Cf. Paul Léon, Du Palais-Royal au Palais-Bourbon. Souvenirs, Paris, A. Michel, 1947, p. 266. Sur l'expérience de Hautecœur en Égypte, voir Mercedes Volait, Les années égyptiennes de Louis Hautecœur ou l'art de la "diplomatie culturelle" en terrain contesté, in Tricia Meehan et Patrice Gourbin (dir.), Relire Louis Hautecoeur, Rouen, Point de vues, 2019, p. 88-97.

9. Cf. L. Hautecœur, Notices sur les membres décédés: Léon (Paul)... op. cit., p. 29. Sur le contexte financier, voir Caroline Piquet, Les réseaux d'affaires en Égypte : patronat européen, minorités 
locales et notables égyptiens dans la réforme et l'industrialisation du pays durant l'entre deuxguerres, in Hubert Bonin, Catherine Hodeir, Jean-François Klein (dir.), L'esprit économique impérial (1830-1970). Groupes de pression \& réseaux du patronat colonial en France \& dans l'empire, Paris, Société française d'histoire d'outre-mer, 2008. p. 633-652.

10. Il s'agit de l'Exposition française inaugurée au Caire en mars 1929. Cf. Égypte-France: Exposition française au Caire, Paris, Impr. de Desfossés-Néogravure, 1929.

11. P. Léon, Du Palais-Royal au Palais-Bourbon, souvenirs... op.cit., p. 207, cit. in Camille Bidaud, La doctrine des Monuments historiques en France d'après Paul Léon (1874-1962), thèse sous la dir. de Jean-Philippe Garric, université Paris-Est, 2018, p. 94-95.

12. Pour un examen plus large des continuités au point de vue de la législation voir Xavier Perrot, «L'Administration législateur. Le cas de l'administration des Beaux-arts et de la production normative patrimoniale et culturelle (1907-1944) », Revue d'histoire des facultés de droit, $\mathrm{n}^{\circ} 31,2011$, p. 269-386.

13. Cf. A. Brucculeri, Louis Hautecœur à la Direction des Beaux-arts, in Jean-Louis Cohen (dir.), Architecture et urbanisme dans la France de Vichy, Paris, Éditions du Collège de France, 2020, p. 43-58, mais voir aussi Id., "Louis Hautecœur, directeur général des Beaux-arts (1940-1944) », Histoire de l'art, $\mathrm{n}^{\circ} 47$, novembre 2000, p. 53-62. Pour une analyse systématique de l'action de Hautecœur à cette époque, cf. Caroline Poulain, La permanence des Beaux-arts dans la fracture de Vichy: l'action de Louis Hautecœur au secrétariat général des Beaux-arts (1940-1944), thèse de l'Ecole nationale des chartes, 2001.

14. Cf. A. Brucculeri, «Dal rigore scientifico all'impegno culturale : Louis Hautecœur e le mostre di storia dell'architettura francese a Strasburgo e Parigi, 1922-1923 ", Annali della Scuola Normale Superiore di Pisa, IV, 1999, IV ${ }^{\mathrm{e}}$ série, fasc. 2, p. 595-613 et Id., Du dessein historique à l'action publique... op. cit., p. 172-183.

15. Discours prononcé par Monsieur Paul Léon, membre de l'Institut, Directeur des Beaux-arts, à l'inauguration de l'Exposition de l'Euvre des architectes de l'École française, Dornach, Braun \& Cie ; Paris, 1922, p. 4.

16. Ibid., p. 6.

17. Cf. P. Léon, «La renaissance de l'architecture gothique», Revue de Paris, XX, t. IV, 10 juillet 1913, p. 115-133 et id., "La querelle des gothiques et des classiques », ibid., 15 juillet 1913, p. 361-386.

18. P. Léon, L'art gothique et les grandes cathédrales, Paris, R. Ducher, 1923.

19. Voir son intervention consacrée à "Les survivances gothiques dans l'architecture du XVII ${ }^{\mathrm{e}}$ siècle " (L'Architecture, XXXV, n 4, 25 février 1922, p. :29-34 et ibid., n 5, 10 mars 1922, p. 37-41), communication intégralement rééditée dans les actes du congrès (Paris, Presses universitaires de France, 1924, t. II, p. 183-192).

20. En février 1920 l'éditeur Payot proposa à Hautecœur un premier projet d'édition pour un ouvrage consacré à «L'architecture française de Henri IV à Napoléon $\mathrm{I}^{\mathrm{er}}$ ». Cf. A. Brucculeri, Du dessein historique à l'action publique... op. cit., p. 114.

21. Cf. Robert de Lasteyrie, L'architecture religieuse en France à l'époque romane: ses origines, son développement, Paris, A. Picard \& fils, 1912, rééd. 1930, et Id., L'architecture religieuse en France à l'époque gothique, Paris, A. Picard, 1926-1927, 2 vol.

22. P. Léon, La vie des monument français, destruction restauration, Paris, A. et J. Picard, 1951.

23. L'éditeur Picard avait manifesté à Hautecœur sa volonté de mettre en valeur la continuité entre les publications de Lasteyrie, Hautecœur et Léon. Lettre de Jacques Picard à Hautecœur du 13 décembre 1949, Bibliothèque de l'Institut de France (BIF), Papiers L. Hautecœur, ms. 6927, f. 83, cit. in A. Brucculeri, Du dessein historique à l'action publique... op. cit., p. 120.

24. Membre de droit de la Commission depuis 1907, lorsqu'il devient chef du Service d'architecture. Cf. C. Bidaud, La doctrine des Monuments historiques en France d'après Paul Léon... op. cit., p. 107. 
25. En dressant un tableau statistique (sans précision de la période considérée) concernant la présence de chaque membre aux séances de la Commission des monuments historiques, Camille Bidaud a mis en évidence le nombre très important de séances auxquelles Léon participe (355, dont 173 présidées par lui-même), concurrencé seulement par l'inspecteur général des Monuments historiques, Paul Boeswillwald (335 séances), et le chef du bureau des M.H., Paul Verdier (325 séances). C. Bidaud, La doctrine des Monuments historiques en France d'après Paul Léon... op. cit., Annexes. a) Statistiques de la Commission des Monuments historiques, p. 2.

26. Arrêté de nomination du 18 avril 1932. Camille Bidaud récense au total 55 séances de la commission auxquelles participa Hautecœur, ce qui n'est pas comparable au rôle joué par Léon dans cette instance. Il faut en tout cas préciser que les originaux des comptes rendus des séances de la Commission des monuments historiques de 1933 à 1940 ont été perdus. La série de doubles, seule trace conservée, est sans doute incomplète.

27. Avec le palais des Papes à Avignon, il s'agit des deux cas de restauration d'édifices les plus cités par Léon pour les travaux d'envergures subis, hormis les restaurations suivies aux destructions de guerre. Cf. C. Bidaud, La doctrine des Monuments historiques en France d'après Paul Léon... op. cit., p. 138.

28. Voir ses deux volumes sur l'Histoire du château de Versailles parus avant et à la fin de la Grande Guerre : le premier consacré à Versailles sous Louis XIV (Paris, A. Marty, 1911) et le second portant sur Versailles au XVIII ${ }^{e}$ siècle (Paris, Émile-Paul, 1918). Sur le topos que Versailles représenta dès la dernière décennie du XIX ${ }^{\mathrm{e}}$ siècle, en tant que creuset de l'héritage culturel d'Ancien Régime et des enjeux de la nation démocratique à l'heure de la Troisième République, voir Kevin L. Justus, Louis XV and Versailles: Selective patrimony in the French Third Republic, Pierre de Nolhac, and the formation of a scholarly tradition, PhD, University of Arizona, 1991.

29. Cf. A. Brucculeri, Du dessein historique à l'action publique... op. cit., vol. I, p. 146 et, pour les programmes des cours de Nolhac et de Hautecœur, voir Lyne Therrien, L'histoire de l'art en France. Genèse d'une discipline universitaire, Paris, CTHS, 1998, p. 489-490.

30. En polémique avec l'architecte Benjamin Chaussemiche. Cf. Arlette Auduc, Quand les monuments construisaient la nation. Le service des monuments historiques de 1830 à 1940, Paris, Comité d'histoire du ministère de la Culture, 2008, p. 438-439.

31. L. Hautecœur, "La conférence d'Athènes pour la protection des Monuments historiques ", L'Architecture, XLIV, n 12, 15 décembre 1931, p. 455. Voir, avec celle de Léon, les contributions de Paul Saintenoy (La restauration des monuments. Principes généraux), Gustavo Giovannoni (La restauration des monuments en Italie) et Leopoldo Torres Balbas (La Restauration des monuments en Espagne), dans La Conservation des monuments d'art et d'histoire, travaux de la Conférence d'Athènes, 21-30 octobre 1931, Paris, Institut international de coopération intellectuelle, s. d. (1933), p. 51-69 et 80-83 (le texte de Giovannoni a été réédité dans : La Conférence d'Athènes sur la conservation artistique et historique des monuments (1931), édition établie par Françoise Choay, Paris, Les Éditions de l'Imprimeur, 2002, p. 57-60).

32. Cf. Emmanuel Pontremoli, «La restauration du palais de Versailles", in La Conservation des monuments... op. cit., p. 286-296. Un bilan des travaux est présenté trois ans auparavant lors du LII Congrès de la Société centrale des architectes. Cf. Patrice Bonnet, « Les récentes restaurations du Château de Versailles ", L'Architecture, XLI, n 9, 15 septembre 1928, p. 287-294. Sur le rôle fondamental des travaux de consolidation et d'entretien du patrimoine de Versailles dans le contexte français depuis la première moitié des années 1920, voir les procès-verbaux des séances de la Commission des Monuments historiques du 15 mai 1923, faisant état d'un véritable bilan des dégradations des différentes parties du palais et de son domaine, et du 10 juillet 1924 : cette dernière séance fut tenue à Versailles et elle porta sur l'emploi des fonds de la donation de John Rockefeller pour la réalisation des travaux (MAP, 80/15/25).

33. Au sujet du cours portant sur Versailles, cf. Annuaire du Collège de France, XL, Paris, Imprimerie Nationale, 1943, p. 81-85. Versailles et ses travaux de restauration, du château jusqu'au parc, 
demeurèrent parmi les spécimens les plus richement abordés et illustrés dans P. Léon, La vie des monument français... op.cit., p. 512-524, fig. 339-362. À propos des leçons sur "Reims-Étude d'histoire urbaine » données dans le cadre du cours de 1933, voir le manuscrit du cours, Archives nationales, 20140260/32 et 20140260/33. Sur la France et " le mythe du gothique » par rapport à la destruction de la cathédrale de Reims pendant la Première Guerre mondiale voir : Thomas W. Gaehtgens, Reims on fire: war and reconciliation between France and Germany, Los Angeles, The Getty Research Institute, 2018, trad. fr. : La cathédrale incendiée. Reims, septembre 1914, Paris, Gallimard, 2018, p. 123-152.

34. Voir les procès-verbaux de la Commission des monuments historiques, séances du 27 juillet 1923 et du 13 février 1925 respectivement, présidées par Léon. Cf. MAP, 80/15/25 et 80/15/26.

35. L'éditeur Armand Colin contacta Hautecœur dès le 26 octobre 1922 au sujet de ce projet éditorial (BIF, Papiers LH, ms. 6921, f. 74). Il s'agit de L. Hautecœur, L'architecture en France de 1789 à 1850 et L'architecture en France de 1850 à nos jours, in André Michel (dir.), Histoire de l'art depuis les premiers temps chrétiens jusqu'à nos jours, Paris, Colin, 1905-1929, 9 t. (18 vol.), t. VIII, vol. 1 (1925), p. 1-44 et vol. 2 (1926), p. 473-507.

36. Commission des Monuments historiques. Ière Section. Séance du 17 décembre 1932. Présidence de M. Ruprich-Robert, compte rendu, p. 1-3, MAP, 80/15/28.

37. À ce propos, on se souviendra des clichés de la citadelle de la ville, pris par l'historien et parus dans le t. II de l'Histoire de l'architecture classique en France (Paris, J. Picard \& C ${ }^{\mathrm{ie}}, 1948,2$ vol., vol. I, fig. 395-396, p. 503-504, et vol. II, table des illustrations, p. 934).

38. Commission des Monuments historiques. 1ère Section. Séance du 27 janvier 1933, procès-verbal, p. 7-8. Voir aussi Commission des Monuments historiques. $1^{\text {ère }}$ Section. Séance du 16 Décembre 1932. Présidence de M. Ruprich-Robert, procès-verbal, n. p., MAP, 80/15/28.

39. Voir le texte de l'arrêté du ministre de l'Éducation nationale, Jean Zay, BIF, Papiers LH, ms. 6886, f. 38. L'arrêté portant création du concours date du 22 décembre 1937, tandis que celui fixant la composition du jury remonte au 3 mai 1937. Cf. ibid. Sur le concours cf. Les concours des monuments historiques de 1893 à 1979, catalogue de l'exposition sous la dir. de Françoise Bercé, Paris, CNMHS, 1981, p. 68-73. Sur les dossiers de quelques candidats (Paquet, Gogois) ainsi que sur l'organisation générale du concours cf. MAP, 80/11/31.

40. Cf. A. Auduc, Quand les monuments construisaient la nation... op. cit., p. 288 et Alphonse Bertrand, Versailles. Ce qu'il fut - ce qu'il est, ce qu'il devrait être, Paris, Plon-Nourrit et C $C^{\text {ie }}, 1906$.

41. Hautecœur rencontra Léon une première fois à Clermont-Ferrand le 28 juillet, et encore le 6 août, le 3 et le 18 septembre. Voir son premier carnet manuscrit (1940) en tant que directeur général des Beaux-arts, BIF, ms. 6888.

42. Cf. L. Hautecœur, Notices sur les membres décédés : Léon (Paul)... op. cit., p. 29.

43. Voir le rapport signé par Hautecœur (29 mai 1942), AN, F/21/8085, cit. in A. Brucculeri, Louis Hautecœur à la Direction des Beaux-arts... op. cit., p. 56. Selon le témoignage de Hautecœur, Joseph Barthélemy, ministre de la justice entre 1941 et 1943, le chargeait de prévenir Léon chaque fois où ce dernier était en danger : " Paul Léon, comme il disait, s'évaporait et ne revenait que le péril passé ». L. Hautecœur, Notices sur les membres décédés : Léon (Paul)... op. cit., p. 29.

44. L. Hautecœur, Les Beaux-arts en France. Passé et avenir, Paris, A. \& J. Picard et Cie, 1948, p. 92.

45. Ibid.

46. Cf. T. Meehan, Le pari de Louis Hautecour : les architectes à la pointe de la bataille sur la ville, in $\mathrm{T}$. Meehan et P. Gourbin (dir.), Relire Louis Hautecœur... op. cit., p. 102 et Ead., Les Bâtiments civils: continuité et consolidation, in J.-L. Cohen (dir.), Architecture et urbanisme dans la France de Vichy... op. cit., p. 64-65.

47. Au sujet notamment du statut professionnel et de la formation d'architecte, dès la proposition de loi du député Liouville en 1921 il fut question de débattre en termes très concrets de la protection du titre d'architecte, alors que les premières tentatives de réforme de la pédagogie Beaux-arts apparurent entre le premier après-guerre et le seuil des années 1930. Cf. 
A. Brucculeri, Du dessein historique à l'action publique... op. cit., p. 297-298. Sur l'action de Hautecœur en ce domaine au début des années 1940, cf. ibid., p. 299-333 et Id., « Révision et hégémonie du système Beaux-arts : réformer l'enseignement de l'architecture à l'heure de Vichy ", Cahiers HEnsA20, $\mathrm{n}^{\circ}$ 8, mai 2020, p. 17-21.

48. Il s'agit des lois du 25 février (protection des abords des monuments), 12 avril (réglementation de l'affichage) et 15 juin 1943 (urbanisme). La défense de la Beauté française est le titre d'une conférence que Hautecœur donna à Vichy le 16 décembre 1943 à la suite d'autres interventions sur le même thème depuis l'année précédente. Cf. A. Brucculeri, Louis Hautecœur, directeur général des Beaux-arts (1940-1944)... op. cit., p. 57 et note 41, p. 61.

49. Cf. Journal Officiel de la République française, LXXII, n 107, 4 mai 1930, p. 5002-5005.

50. MAP, fonds Paul Léon, carton 0080/047/003.

51. P. Léon, Du Palais-Royal au Palais-Bourbon, souvenirs... op. cit., p. 219.

52. L. Hautecœur, Les Beaux-arts en France... op. cit., p. 20-21, extrait plus largement cité dans A. Brucculeri, Louis Hautecœur, directeur général des Beaux-arts... op. cit., p. 58.

53. Sur Huisman, cf. Hélène Serre de Talhouet, Placé pour être utile: Georges Huisman à la Direction Générale des Beaux-arts (1934-1940), thèse sous la dir. de François Robichon, université Lille III, 2015. 54. Le 4 février 1934, suite à la nomination de Bollaert au poste de préfet du département du Rhône. Cf. H. Serre de Talhouet, Placé pour être utile : Georges Huisman... op. cit., p. 112.

55. Nous rappelons que Herriot fut chef du gouvernement du 3 juin au 14 décembre 1932, suite à des élections législatives marquant la victoire de la gauche. Le décret de nomination de Bollaert est daté du 13 décembre 1932. Cf. H. Serre de Talhouet, Placé pour être utile : Georges Huisman... op. cit., p. 111. Bollaert s'engagea dans la Résistance pendant la Seconde Guerre mondiale. Quant à Huisman, il était proche de Jean Zay et fut même arrêté par les Allemands en 1942.

56. Cf. A. Auduc, Quand les monuments construisaient la nation... op.cit., p. 16. Tricia Meehan a souligné une nouvelle fois l'importance de cette « longévité ». Cf. T. Meehan, Les Bâtiment civils... op. cit., p. 63-66, et Ead., Le pari de Hautecour... op. cit., p. 98-109.

57. Cette année-là Hautecœur avait connu Léon « chez un ami commun » une fois quitté l'hôpital de la Pitié-Salpêtrière où il avait été évacué le 8 décembre 1915 après avoir été blessé en guerre. Cf. L. Hautecœur, Notices sur les membres décédés : Léon (Paul)... op. cit., p. 29.

58. Cf. P. Léon, La Guerre et l'architecture. La Renaissance des ruines; maisons, monuments, Paris, H. Laurens, 1918 et A. Auduc, «Paul Léon, le service des Monuments historiques et la reconstruction. Enjeux et cadre institutionnel». in Nicholas Bullock et Luc Verpoest (dir.), Living with History, 1914-1964 : Rebuilding Europe after the First and Second World Wars, and the Role of Heritage Preservation, Louvain, Leuven University Press, 2011, p. 72-85.

59. C'est l'intitulé du troisième et dernier chapitre de l'ouvrage La Guerre et l'architecture, maintenant dans C. Bidaud, "Anthologie de textes rares de Paul Léon sur la restauration monumentale", Les Cahiers de la recherche architecturale, urbaine et paysagère, https:// journals.openedition.org/craup/4126, consulté le 24 octobre 2020.

60. Le logis et la maison des champs. Exposition de l'architecture régionale dans les provinces envahies (10 janvier-10 février 1917). Conférences et compte rendu, Paris, Impr. L. Maretheux, 1917. Cf. Jean-Claude Vigato, L'architecture régionaliste. France 1890-1950, Paris, Norma, 1994, p. 93-102.

61. À ce propos, voir A. Brucculeri, Du dessein historique à l'action publique... op. cit., p. 229-278. Sur l'histoire de cette revue cf. Id., Le "Journal de la Société": genèse et évolutions d'une revue pour l'architecture, in Jean-Pierre Péneau et Marilena Kourniati (dir.), Archives, acteurs et institutions, actes des journées d'études du 15 et 16 octobre 2015, Paris, Académie d'Architecture, 2017, p. 62-70.

62. L. Hautecœur, « Maisons ouvrières ", L'Architecture, XXXVI, nº 6, 25 mars 1923, p. 73-78.

63. Pierre Schommer, "La reconstruction des places d'Arras", L'Architecture, XXXVII, $\mathrm{n}^{\circ} 20$, 25 octobre 1924, p. 276-282. Arras est encore parmi les exemples abordés par Léon dans son ouvrage La Vie des Monuments français (p. 503-505). 
64. L. Hautecœur, "Architecture et régionalisme ", L'Architecture française, vol. 3, janvier 1942, p. 4.

65. Id., Journal de Genève, CXXII, n 307, 30 décembre 1947, p. 3, col. 1-4.

66. Dans ce domaine se situent les principaux projets de restauration au lendemain de la Grande Guerre tels ceux de la cathédrale et de l'église Saint-Rémi de Reims. Cf. C. Bidaud, «Des expérimentations légitimées par le traumatisme: Paul Léon à Saint-Rémi de Reims ", In Situ. Revue des patrimoines, 23 (2014), p.1-18 et Ead., La doctrine des monuments historiques en France d'après Paul Léon... op.cit., p. 143-174. Sur la cathédrale de Reims en particulier, cf. T. W. Gaehtgens, La cathédrale incendiée... op. cit., p. 197-239.

67. Cf. Roberto Gargiani, Auguste Perret : la théorie et l'œuvre, Paris-Milan, Gallimard-Electa, 1994 (éd. it. 1993), p. 118-123 et Simon Texier, Églises, in Joseph Abram, Jean-Louis Cohen et Guy Lambert (dir.), Encyclopédie Perret, Paris, Éditions du Patrimoine, 2002, p. 139-144.

68. P. Léon, La Guerre et l'architecture... op. cit., p. 83.

69. Cf. A. Brucculeri, Du dessein historique à l'action publique... op. cit., p. 194-217.

70. Le verbe être est rayé et remplacé par paraître dans le texte dactylographié. P. Léon, État des lieux de l'architecture, texte de la conférence donnée le 8 mai 1934 au Collège de France, p. 3. AN, 20140260.34.

71. Cf. ibid.

72. Cf. ibid., p. 2. Dans ce contexte Léon évoque, par exemple, ses rapports avec «mon confrère Henri Prost ", architecte élu membre de l'Académie des Beaux-arts.

73. P. Léon, État des lieux de l'architecture... op. cit., p. 2.

74. Cf. ibid., p. 5 et 17.

75. Ibid., p. 4-5.

76. L. Hautecœur, «Introduction ", in L'Euvre des architectes de l'école française du milieu du XVII siècle à nos jours. Juin-sept. 1922, s. 1., s. d. [1922], p. 13.

77. Id., «Préface ", dans Exposition d'architecture française, Paris, Société artistique de publications techniques [1933], texte également paru dans L'Architecture, XLVI, n 12, 15 décembre 1933, p. 413-414 et dans : Le Bâtiment illustré, IX, décembre 1933, s. p.

78. Cf. ibid., p. 413.

79. Voir la lettre du $1^{\text {er }}$ août 1912 par laquelle le ministre du Commerce et de l'Industrie informa Léon de sa nomination en tant que "Membre de la Commission chargée d'étudier les moyens d'organiser à Paris, en 1916, une Exposition Internationale des Arts décoratifs modernes ». AN, 20140260.

80. Voir la lettre du Commissaire général de l'Exposition, adressée le 26 février 1924 à « Monsieur Hautecœur, Industriel, Amateur d'Art", BIF, Papiers LH, ms.6898, f. 233. La classe I (Architecture) étaient présidée par Emmanuel Pontremoli. Eugène Freyssinet, Charles Lemaresquier et Auguste Perret en étaient les vice-présidents et André Ventre le rapporteur. Cf. Exposition Internationale des Arts décoratifs et industriels modernes. Catalogue Général Officiel. Paris, avril-octobre 1925, Paris, Imprimerie de Vaugirard, 1925, p. 29.

81. Des épreuves corrigées du volume I du rapport sont conservées dans les papiers de Léon, voir AN, 20140260.

82. P. Léon, État des lieux de l'architecture... op. cit., p. 20.

83. Les vicissitudes de la soumission du projet de 1931 de Le Corbusier pour l'Exposition internationale de 1937 sont exemplaires, avec le rebondissement sans succès de 1934, lorsque Léon apparaît comme l'un des interlocuteurs de l'architecte. Cf. H. Serre de Talhouet, Placé pour être utile: Georges Huisman... op. cit., p. 218-219. Bien que Léon n'en rapporte aucun souvenir dans ses mémoires (P. Léon, Du Palais-Royal au Palais-Bourbon, souvenirs... op.cit.), il n'en demeure pas moins qu'en 1925 le pavillon de l'Esprit Nouveau fut occulté par une palissade par le commissariat général et que cette palissade disparut seulement à l'occasion de la visite du ministre de l'Instruction publique, Anatole de Monzie, personnalité ouvertement opposée à Léon. 
Sur l'évolution assez rapide, entre 1922 et 1923, des positions de Hautecœur à propos de Le Corbusier et de sa vision de l'architecture et de la ville, cf. A. Brucculeri, Du dessein historique à l'action publique... op. cit., p. 255-256.

84. Cf. Jean-François Pinchon, La conception et l'organisation de l'exposition, in Bertrand Lemoine (dir.), Cinquantenaire de l'exposition internationale des arts et des techniques dans la vie moderne, Paris, IFA/Paris-Musées, 1987, p. 36-43.

85. Cf. A. Brucculeri, Du dessein historique à l'action publique... op. cit., p. 221.

86. Vitraux modernes à l'Exposition 1937, avant-propos de Paul Léon, introduction de Robert MalletStevens, Paris, C. Moreau, 1937. Léon était d'ailleurs le beau-père de Mallet-Stevens.

87. Cf. Cécile Buffat, "La Fée Électricité de Dufy et le mécénat électrique dans l'entre-deuxguerres ", Annales historiques de l'Électricité, n 4, novembre 2006, p. 63.

88. Cf. Florence Riou, « Le cinéma à l'Exposition internationale de 1937 : un média au service de la recherche scientifique ", 1895. Revue de l'association française de recherche sur l'histoire du cinéma, $\mathrm{n}^{\circ} 58$, octobre 2009, p. 34.

89. L. Hautecœur, L'Architecture à l'Exposition de 1937, texte manuscrit, BIF, Papiers L. Hautecœur, ms. 6909, f. 251 (p. 17).

90. P. Léon, La restauration des monuments en France... op. cit., p. 58.

91. Id., L'esprit moderne dans les arts décoratifs et industriels, in Exposition internationale des arts décoratifs et industriels modernes, Paris 1925 : rapport général. Section artistique et technique, Paris, Librairie Larousse, 1931, t. I, Préface : Origines de l'Exposition et évolution de l'art moderne, p. 12. 92. P. Léon, Préface, dans Albert Keim, Les styles. L'art ancien dans l'ameublement. La rétrospective du lit, les sièges et meubles de styles, le mobilier rustique et la décoration intérieure. Faïences, ferronnerie, luminaire, Clermont-Ferrand, Société Mont-Louis, 1937, p. 1.

93. Voir l'exemplaire du livre de communication de la section française à l'Exposition internationale de 1939 à New York, conservé dans les papiers de P. Léon. AN, 20140260/54.

94. Compagnie Luxembourgeoise de Radiodiffusion. Ce que laissera l'Exposition par M. Louis Hautecour, conservateur du Musée national du Luxembourg (20 avril 1935), BIF, ms. 6909, dactyl., f. 191 (p. 4).

\section{RÉSUMÉS}

Cet article met en évidence la dette multiple de Louis Hautecœur envers Paul Léon au travers et au-delà du rôle que tous les deux jouèrent à la tête de l'administration des Beaux-Arts en France. L'objet principal du legs de Léon dans les idées et dans l'action de Hautecœur est identifié dans la convergence que le premier instaura entre le domaine d'intervention concernant la protection $\mathrm{du}$ patrimoine et celui visant le projet d'architecture et ses acteurs. Il est d'abord question d'éclairer des approches historiographiques partagées à la lumière desquelles une vision élargie du corpus des monuments nationaux est pointée, de même qu'une interprétation commune de l'idée de modernité de l'architecture entre passé et présent. L'investissement de l'un et de l'autre dans le domaine des expositions internationales parisiennes d'entre-deux-guerres, est porté en témoignage exemplaire de leur commune manière d'entendre l'articulation des temporalités des productions artistiques nationales.

This essay focuses on the multiple intellectual debts of Louis Hautecœur to Paul Léon through the lens of the role they both played at the head of the administration of the Fine Arts in France. Léon's legacy in the ideas and actions of Hautecœur can be identified mainly in the convergence 
between the field of intervention concerning the protection of heritage and that of the architectural project and its actors. First of all, the question is to single out the historiographical approaches they shared so as to understand how these influenced their vision of the corpus of national monuments, as well as their mutual interpretation of the idea of modernity of architecture between past and present. In this context, the analysis of their involvement in the field of international Parisian exhibitions of the interwar period is presented as an exemplary testimony of how similar their comprehension of the articulation of the temporalities of national artistic production was.

Dieser Beitrag beschäftigt sich mit dem vielschichtigen Einfluss, den das Wirken Paul Léons als Leiters der Direction des Beaux-Arts auf die Arbeit seines Nachfolgers Louis de Hautecœur ausgeübt hat. Als wesentliches Erbe Léons, das sich in den Gedanken und den Tätigkeiten Hautecœurs widerspiegelt, kann das von Léon erzielte Zusammenwirken von Denkmalpflege und architektonischem Schaffen gelten. Daher soll es zunächst darum gehen, die jeweiligen historiographischen Herangehensweisen $\mathrm{zu}$ untersuchen, denen ein weit gefasster Denkmalbegriff zu Grunde liegt, sowie die gemeinsame Deutung des Wesens moderner Architektur im Spannungsfeld von Vergangenheit und Gegenwart. Darüber hinaus soll die Tätigkeit Leóns und Hauteœurs im Rahmen der Pariser Weltausstellungen in der Zwischenkriegszeit beleuchtet werden, die von ihrem gemeinsamen Bewusstsein der zeitlichen Gebundenheit eines als "national" bezeichneten künstlerischen Schaffens zeugt.

\section{INDEX}

Mots-clés : administration, Beaux-Arts, Expositions internationales, historiographie architecturale, Monuments historiques, protection patrimoniale, reconstruction, Régionalisme, restauration, Louis Hautecoeur, Paul Léon

\section{AUTEUR}

\section{ANTONIO BRUCCULERI}

Diplômé de l'université IUAV de Venise, Antonio Brucculeri a soutenu une thèse consacrée à l'œuvre et à l'action de Louis Hautecœur, ayant fait l'objet d'un ouvrage (Paris, Picard, 2007). Spécialiste de l'histoire architecturale et urbaine de la fin du XVIIIe siècle aux premières décennies du $\mathrm{XX}^{\mathrm{e}}$ siècle, son activité de recherche privilégie la problématique des rapports entre traditions et modernités et les terrains de l'historiographie architecturale et de la formation de l'architecte. Chargé de conférences à l'École Pratique des Hautes Études (2009-14), professeur invité à l'université Ca' Foscari de Venise (2012-13) et boursier au Paul Mellon Center de Londres (2007 et 2013-2014), il est maitre de conférences à l'ENSA Paris-Val de Seine, chercheur au laboratoire EVCAU (ENSAPVS) et chercheur associé à l'EPHE (équipe HISTARA). Adresse électronique : brucculeri.ensapvs@gmail.com 